The University of Maine

DigitalCommons@UMaine

Publications

Senator George J. Mitchell Center for Sustainability

Solutions

$4-2014$

\title{
Different open-canopy vegetation types affect matrix permeability for a dispersing forest amphibian
}

Brittany Cline

University of Maine

Malcolm L. Hunter Jr.

University of Maine, mhunter@maine.edu

Follow this and additional works at: https://digitalcommons.library.umaine.edu/ mitchellcenter_pubs

Part of the Terrestrial and Aquatic Ecology Commons

\section{Repository Citation}

Cline, Brittany and Hunter Jr., Malcolm L., "Different open-canopy vegetation types affect matrix permeability for a dispersing forest amphibian" (2014). Publications. 24.

https://digitalcommons.library.umaine.edu/mitchellcenter_pubs/24

This Article is brought to you for free and open access by DigitalCommons@UMaine. It has been accepted for inclusion in Publications by an authorized administrator of DigitalCommons@UMaine. For more information, please contact um.library.technical.services@maine.edu. 
Different open-canopy vegetation types affect matrix permeability for a dispersing forest amphibian

Brittany B. Cline* and Malcolm L. Hunter Jr

Department of Wildlife Ecology, University of Maine, 5755 Nutting Hall, Orono, ME 04469 USA 
1. Population viability often depends on conserving functional connectivity in fragmented landscapes. For pool-breeding amphibians, population connectivity is largely maintained through juvenile dispersal, often through various vegetation types that may differ as filters or conduits to movement.

2. We quantified the relative permeability of different types of open-canopy vegetation to juvenile wood frogs Lithobates sylvaticus to determine whether this influences functional connectivity during dispersal.

3. We conducted experimental releases of juveniles $(n=561)$ in ten runways representing five treatments: hayfield, moderate-cover lawn (45-85\% cover), open lawn ( $0 \%$ cover), row crop (forage-corn) and recent clear-cut. Runways consisted of $35 \times 2.5$ m enclosures, located perpendicular to a forest edge and extending into treatment areas with tracking stations at 10, 20 and $30 \mathrm{~m}$. As indices of permeability, we measured the number of animals traversing each station, the proportion changing direction, movement timing and movement rates.

4. Based on an index that compounds four metrics and scales them relative to mature forest as a control, permeability varied between open-canopy cover types in the following order: row crop < hayfield < clear-cut < open lawn < moderate-cover lawn.

5. The highest proportions of individuals changed direction (towards forest) in the hayfield, moderate-cover lawn and clear-cut, suggesting that juveniles may make forays into the open and subsequently assess habitat. Nonetheless, individuals could eventually transit entire runways, indicated by overall recaptures at $30 \mathrm{~m}$ (e.g. hayfield, 29\%; moderate-cover lawn, 24\%; and clear-cut, $20 \%$ ) at the end of our six-week experiment.

6. Synthesis and applications. We provide quantitative evidence that open-canopy cover types may act as differential ecological filters to ranging movements, and ultimately dispersal. Differences in the willingness of animals to enter treatments, coupled with motility and residency times, support the differing roles of open-canopy vegetation as both filters and conduits to movement. Thus, it may be overly simplistic to estimate matrix permeability as uniformly low in models that predict movement in fragmented landscapes. To promote functional connectivity, modification of vegetation composition and configuration may provide an underutilized tool for conservation practitioners to reduce the effective isolation of habitat patches for post-metamorphic amphibians. 


\section{INTRODUCTION}

For many species, quantifying functional connectivity between preferred habitats is critical for understanding the mechanisms that drive long-term population persistence in fragmented landscapes (Revilla et al. 2004; Van Buskirk 2012). It is widely recognized that population viability is maintained by dispersal among breeding sites (Hudgens et al. 2012) and, further, that successful dispersal depends For many species, quantifying functional connectivity on the characteristics of the matrix that intervenes between preferred habitats is critical for understanding the suitable habitats and the interaction of landscape structure mechanisms that drive long-term population persistence in with species-specific behaviour (Burgess, Treml \& Marshall 2012). Despite this critical relationship, conventional assumptions of patch-matrix models often oversimplify the matrix of non-preferred habitats as singularly unsuitable (Kuefler et al. 2010). In reality, the type of matrix may influence the probability of an animal entering the matrix, the speed of movement and ultimate dispersal success. Researchers increasingly acknowledge that there are grades of matrix condition that differ as filters or conduits for movement (Zeller, McGarigal \& Whiteley 2012). However, quantifying this variation in matrix permeability (or conversely, resistance) remains a fundamental challenge. Furthermore, some species might prefer matrix conditions during dispersal even though they differ from preferred conditions for settlement. In this context, it would make sense to refer to 'dispersal habitat' and 'breeding habitat' instead of a matrix of non-habitat interspersed by patches of suitable habitat.

The accelerating conversion of natural ecosystems to human-dominated land cover (Desrochers, Kerr \& Currie 2011) heightens the need to consider diverse cover types that may constitute dispersal habitat. It is possible that for some species, human-determined open-canopy cover types may be acceptable for dispersal (i.e. low travel costs) and thus maintain functional connectivity. In particular, Kuefler et al. (2010) have pointed out that deterrents to movement at boundaries (e.g. perceived risks of entering an open-canopy cover type due to predation) might be mitigated by faster locomotion after these edges are crossed. Furthermore, animals of the same species may prefer different vegetation types for movements depending on the behavioural context (e.g. risk of predation vs. thermal stress in a particular time or place). There is a need to quantify vegetation-type specific movement and boundary behaviours.

Amphibians are appropriate taxa for studying this issue because their movements are typically at tractable scales and because many species rely on aquatic and terrestrial habitat connectivity. In particular, juveniles typically emerge into the terrestrial environment from their natal pool soon after metamorphosis, sometimes emigrating to a new breeding pool (dispersal) and sometimes returning to breed in their natal pool (philopatry). Both dispersing and philopatric juveniles may need to transit heterogeneous vegetation, but dispersers are likely to cover greater distances and be more likely to encounter diverse vegetation (Clobert et al. 2009).

Most permeability studies have relied on expert-derived estimates for models and simulations of structural and functional connectivity (e.g. Hudgens et al. 2012). Some studies have quantified the relative permeability of habitats to juvenile amphibians, especially in forests (e.g. Rothermel \& Semlitsch 2002; Rittenhouse \& Semlitsch 2006), but none have directly measured the permeability of different open-canopy cover types. Prior dispersal research in agricultural, recreational (e.g. golf course) or urbanizing landscapes has focused on 
individual orientation (Vos et al. 2007), landscape and site-specific factors affecting occupancy (Revilla et al. 2004), or resistance of the matrix to gene flow (Van Buskirk 2012). If habitat permeability declines for forest amphibians after timber harvest, at least temporarily (Semlitsch et al. 2008), it is reasonable to presume that the conversion of forest to agricultural or suburban lands might reduce functional connectivity.

\section{STUDY SPECIES AND GOAL}

In this study, we quantified the relative permeability of open-canopy cover types to juvenile wood frogs Lithobates sylvaticus during the post-metamorphic period when they leave natal pools. They are highly sensitive to forest removal and avoid proximity to forest edges (deMaynadier \& Hunter 1998). Dispersal success (i.e. juveniles surviving to breed in new sites) has been estimated at 18- 20\% (Berven \& Grudzien 1990). Dispersal distances have been recorded at > $1000 \mathrm{~m}$ (females: $1140 \pm 324 \mathrm{~m}$; males: $1276 \pm 435 \mathrm{~m}$ ), with a maximum of $2530 \mathrm{~m}$ (Semlitsch \& Bodie 2003). The scale of overland movements may make this species particularly vulnerable to loss of connectivity.

We undertook experiments on the movements of juvenile L. sylvaticus in open-canopy cover as an extension of a prior study on movements through forestry treatments (Popescu \& Hunter 2011). Our goal was to document movement patterns through five types of open-canopy vegetation resulting from forest (clear-cutting), suburban (open-canopy and moderate-cover lawns) and agricultural (row crop, hayfield) practices. Our guiding hypothesis was that these open-canopy cover types differ as filters or conduits for dispersal. In the next section, we describe how movement behaviour leads to dispersal. Then, we develop a predictive framework for permeability (or conversely, resistance), in which we specify a priori hypotheses about differences in post-metamorphic movements between treatments.

\section{POST-METAMORPHIC MOVEMENTS}

Increasingly, animal ecologists employ a behavioural landscape view in which movement is an adaptation to spatiotemporal variation in resource distribution (Beelisle 2005). As such, dispersal movement is shaped both by external factors and individual traits, including morphological, life history-based, behavioural or physiological attributes, often likened to a dispersal 'syndrome' (Clobert et al. 2009). To conceptualize post-metamorphic movement of L. sylvaticus, we first recognize two types of movement, based on Dingle (1996), which can be construed as opposite ends of a continuum. Migration movements tend to be towards distant resources and are not directly responsive to proximate resources (e.g. Dingle \& Drake 2007). For example, annual journeys of adult wood frogs from hibernaculum to breeding pools are migrations primarily because they are directed towards breeding sites and not resources along the route. In contrast, movements that are directed towards an animal's need for immediate resources are termed 'station-keeping'; seeking a suitable microclimate is an example. An intermediate form of movement is 'ranging', in which an individual departs from a location, travels moderate distances seeking resources and occupies the first suitable patch of habitat encountered. We speculate that post-metamorphic frogs are largely driven by 'ranging', in which individuals leave their natal pool, make exploratory movements seeking food and an appropriate microclimate and cease when suitable habitat is found (Bowler \& Benton 2005). Over time, ranging movements that are relatively long or repeated may ultimately lead to dispersal to a new breeding pool; shorter ranging movements may result in philopatry. The exploratory nature of ranging suggests that movements may be highly influenced by the ability of individuals to detect environmental conditions from 
some distance and move towards or away from them. Key environmental factors probably include vegetation structure, microclimate, food, predators and conspecifics.

\section{A PREDICTIVE FRAMEWORK FOR PERMEABILITY}

At the study outset, we predicted that several factors might influence the observed patterns of permeability, or resistance. We defined permeability and resistance as broad, converse measures of the degree to which the vegetation (or larger landscape) either facilitates or impedes (respectively) an organism's movement between resources or preferred habitat patches (e.g. Beelisle 2005). Broadly, we predicted that movements would be facilitated (i.e. more willingness to enter or traverse greater distances at greater velocities) through vegetation that was more similar to forest, the species' terrestrial settling habitat (Eycott et al. 2012). Prior studies indicate that amphibians modify movements (e.g. velocity, latency, path tortuosity, willingness to enter habitats) in response to ground substrate, habitat extent (Rothermel \& Semlitsch 2002), vegetation structure, microclimate (Rittenhouse et al. 2008) and physiological factors such as stress-hormone levels (Janin et al. 2012).

Specifically, we predicted that the most open and least structurally complex cover types (open lawn, row crop) would be less permeable than types with greater canopy cover and structural complexity (moderate-cover lawn, hayfield, clear-cut). Permeability in this context has three key elements that we can measure, which depend on the interaction between individual behaviour and vegetation structure: (1) willingness to enter a vegetation type, (2) probability of crossing the vegetation type, and (3) velocity. There are some likely trade-offs between the factors that collectively influence movement success. For example, a frog may be more willing to enter dense vegetation with a lower risk of desiccation even though thick vegetation will impede its velocity and thus increase the time it is outside the forest.

Recognizing these trade-offs, we predicted that frogs in open lawns or row crops would (1) demonstrate low willingness to enter, (2) traverse only short distances and (3) move faster, compared with moderate-cover lawns, hayfields or clear-cuts. More specifically, we expected to observe a greater proportion of animals returning to the nearest forest edge when released in our most open treatments (lawns or cornfields), while a greater proportion of animals would be recaptured or tracked at distances extending into hayfields or clear-cuts, where increased habitat structure might afford cool moist microclimates or cover from predators. However, we also predicted high movement rates for (and large distances traversed by) the proportion of animals venturing into cornfields and lawns, if simplified vegetation structure represented low impedance for locomotion. Finally, we predicted that the timing of movements in hayfield and clear-cut might be protracted if locomotion was slow due to thick ground vegetation and individuals perceived these treatments as a refuge with suitable microclimates and lower predation risk.

Materials and methods

\section{STUDY SITES AND EXPERIMENTAL DESIGN}

We conducted this experiment in Penobscot County, Maine, USA, on lands managed by the University of Maine's Agricultural and Forest Experiment Station. Extensive forest management in the Acadian Forest region has generated a mosaic of mixed-wood stands of various age classes. Our study area is in the lower Penobscot River watershed $\left(9974 \mathrm{~km}^{2}\right.$ ), where $78.3 \%$ of the landscape is forested (of which $20.4 \%$ has recently been cut), $3.9 \%$ is urban, $3.9 \%$ is agriculture and the balance is water bodies and wetlands. We selected five open-canopy treatments that typify the region: (1) hayfield, (2) moderate-cover lawn ( 45-85\% cover by ornamental trees), (3) open lawn (0\% cover), (4) row crop (silage corn) and (5) recent clear-cut (3-5 
years). The hayfield constituted a mixture of grasses and legumes, with average stem height of $0.87 \mathrm{~m}$; baling occurred on 23 July 2010, but a continuous swath of hay was retained within and between treatments and extending $>10 \mathrm{~m}$ in all directions from edges. The lawn treatments (hereafter open lawn or moderate-cover lawn) compressed exotic grasses; no mowing occurred during the study (7 July-5 August 2010). The row crop treatment (hereafter cornfield) comprised feed corn, sown in late May. The inter-row distance averaged 1.1 $\mathrm{m}$ (range: $0.40-2.58 \mathrm{~m}$ ). The forest clear-cut (hereafter clear-cut) was characterized by complete overstorey removal ( $0 \%$ canopy cover), an herbaceous stratum $<50 \mathrm{~cm}$, and lacked tree regeneration.

\section{EXPERIMENTAL RUNWAYS}

Runways were a modification of the design of Popescu and Hunter (2011): 35 X 2.5 m silt-fence enclosures (60 cm height; $15-20 \mathrm{~cm}$ into ground). Our experimental units constituted individual batches of frogs (released in six batches over 6 weeks), nested within five treatments and ten runways (two per treatment). Each runway was located along a perpendicular edge between closed-canopy forest (not harvested in $>20$ years) and each treatment. Location of each runway along the edge was selected randomly and 35-50 m from its replicate. Inside each runway, we constructed three identical tracking stations at 10,20 and $30 \mathrm{~m}$ from the forest edge. Tracking stations constituted plastic containers ( $45 \times 65 \times 20 \mathrm{~cm})$, which were placed in the mouth of a silt-fence funnel (Fig. 1). Each station sheltered two pieces of paper: a waterproof paper coated in a mix of mineral oil and orange fluorescent powder, placed just in advance of a white sheet of paper $(20.3 \times 43.2 \mathrm{~cm})$. Frogs passing through stations would leave their tracks on the white paper; the $20-\mathrm{cm}$ height of the box ensured that frogs could not jump over stations. Each sheet was changed daily, and we employed double-observer methods to record the unidirectional passages of individuals through stations.

Each runway contained 10 pitfall traps (Fig. 1): two at the start and two at the end, and two at the junction of each silt-fence funnel and runway wall. We used pitfalls to estimate the number of individuals reaching the end of runways ( $35 \mathrm{~m}$, that is, indicative of open-cover permeability), vs. returning to the edge $(0 \mathrm{~m})$, or changing movement direction (10 or $20 \mathrm{~m}$ ), all indicative of open-cover avoidance.

\section{JUVENILE AMPHIBIAN REARING AND RELEASE}

We collected L. sylvaticus egg masses from the University of Maine's Penobscot Experimental Forest, Maine, USA, and raised these in plastic wading pools at a forested site until hatching. When larvae reached Gosner (1960) stages $21-23$, we moved them to 1500-L cattle tanks (80 per tank) established as semi-natural meso-cosms. At larval stages $\geq 42$, individuals were moved into large plastic bins (200-L; moist leaf litter) until metamorphosis (stage 47). Prior to each release, we measured (snout-vent length), marked (single toe clip per batch) and randomly assigned frogs to treatments. We released $561 \mathrm{~L}$. sylvaticus across six batches. Within each runway, we released 7-12 animals per batch (consistent within batches). Frogs were released $5.5 \mathrm{~m}$ from forest edge in the centre of each runway ( $2.5 \mathrm{~m}$ from the side walls) $1-2 \mathrm{~h}$ after sunset; we released a subsequent batch only after track sheets denoted no new tracks ( $\geq 1$ day). By waiting 3-6 days before beginning a new batch, most frogs from prior releases had been recaptured or had moved beyond the first runway compartment (minimizing the possibility of density-dependent effects). Runways were monitored 06:30-11:00 h (9 July-7 August 2010).

\section{MICROHABITAT AND MICROCLIMATE VARIABLES}

We collected temperature, relative humidity and daily precipitation in our five treatments using 26 iButton data loggers (Maxim, Inc., Dallas Texas, USA). In the middle compartment of each runway (10-20 m), we measured hourly temperature (1) at ground level, (2) under refugia (i.e. 5-8 cm below coarse woody 
material in clear-cut, under root masses in hayfield, etc.) and (3) $120 \mathrm{~cm}$ above-ground in shade. We measured (4) relative humidity (ground level). Refugia temperatures were not obtained in lawn due to lack of microcover. We also collected microhabitat data, characterizing vegetation in terms of ground cover, canopy closure, vegetation height, stem density and inter-row distance. Habitat characteristics of the hayfield, cornfield and lawn were collected on 16, 22 and 29 July 2010 to account for vegetation growth.

\section{STATISTICAL ANALYSES}

Our experimental design generated four indices to quantify permeability of treatments: (1) the proportion of tracks at each station $(10,20,30 \mathrm{~m}),(2)$ the proportion of animals captured in pitfall traps, (3) movement timing and (4) movement rate. The first two metrics indicate an individual's willingness to enter a given treatment; the third and fourth metrics are joint estimates of velocity within that cover type. All four metrics collectively comprise a measure of cover-type permeability.

For the first index, our dependent variable was the proportion of frogs that reach each station (using tracks to infer the number of single passages of individuals) out of the total released per runway. We assessed whether (1) treatment, (2) individual runway or (3) batch affected the number of tracks recorded (10, 20, 30 $\mathrm{m}$ from forest edge) using our observed values, generalized linear mixed-effects models (GLME) and generalized linear models (GLM). Thus, we ran models for each distance $(10,20,30 \mathrm{~m})$ to avoid autocorrelation (i.e. same individuals counted in successive stations).

We analysed our second index (proportion of animals recaptured among treatments) by distance classes ( 0 , $10,20,30-35 \mathrm{~m}$ ), using three-way contingency tables and pairwise tests for proportions. We quantified this as the proportion of juveniles that were recaptured at each distance $(0,10,20,30-35 \mathrm{~m})$, out of the total reaching each station (from track counts; index \#1). Because the pitfall traps at 30 and $35 \mathrm{~m}$ were located in the same compartment (Fig. 1), we pooled their data. Further, the number of animals captured within the 0 and 30-35 m classes was compared to the total number of released for that runway. We evaluated the relationship between capture frequency and distance, testing for non-independence. We employed pairwise tests for proportions and chi-square tests to estimate differences in capture frequency between treatments at each distance.

Finally, we evaluated potential differences in movement timing and rate (indices \#3-4, or velocity). First, we evaluated movement timing 1-5 days following release using the number of tracks in each station as a proportion of the total number of tracks recorded per runway. We only used data from juveniles $(n=54)$ captured past the first $(10 \mathrm{~m})$ station. We evaluated potential differences in timing between treatments using a non-parametric (chi-squared) Kruskall-Wallis test for proportions [R package (coin); Hothorn et al. 2008]. Secondly, we evaluated velocity in each treatment ( $m$ day-1) using data from 294 individuals that were tracked past the first stations. We used total track counts (i.e. the series of tracks comprising the passage of a single individual through 10-, 20-or 30-m stations) to determine the total minimum distance traversed across the entire experiment (this constituted 4740 total $\mathrm{m}$ in 10 runways and 27 tracking days and did not represent a single individual's passage through consecutive stations). We then pooled distances by treatment to obtain average rates (i.e. total number of $m$ traversed in each treatment divided by the number of days during which movement occurred) and investigated potential differences between treatments using a one-way analysis of variance [ANOVA, R package (car); Fox \& Weisberg 2011]. We modelled rate (m day-1)as a correlate of the willingness of individuals to enter using a simple linear regression model (Pearson's linear correlation coefficient $r$ ). We parameterized willingness to enter using the observed propor- 
tion recaptured at 10,20 or $30-35 \mathrm{~m}$ (but not those that demonstrated avoidance at $0 \mathrm{~m}$ ), of the total released in that treatment.

We computed a composite index of permeability that incorporated all four movement metrics, giving equal weight to each. We assumed that juvenile wood frog movements would be facilitated (i.e. have highest permeability values) through mature forest (i.e. terrestrial settling habitat) based on the study by Popescu and Hunter (2011) and thus used their results (obtained using the same methodology and species in the same locale) as a benchmark of permeability. See Appendix S2.

We assessed potential differences in the size of metamorphs (SVL) released among treatments using a one-way analysis of variance (ANOVA; program R, version 2.13.2). All statistical tests were deemed significant at $\mathrm{P}<0.05$.

\section{RESULTS}

We quantified differences in the relative permeabilities of open-canopy types (hayfields, lawns, row crops and clear-cuts) to juvenile $L$. sylvaticus during post-metamorphosis using four metrics of movement as described in the next three sections. An index derived from these four metrics suggested the following order of permeability (lowest to highest): 1 . row crop (0.40), 2. hayfield (0.47), 3. forest clear-cut (0.55), 4. open lawn (0.58) and 5. moderate-cover lawn (0.67; Appendix S2). Across treatments and experimental releases (batches), the average size (SVL) of juveniles was $16.2 \pm 1.1 \mathrm{~mm}$, with no differences between treatments (ANOVA; $F_{4,176}=1.57, P=0.183$ ).

\section{WILLINGNESS TO ENTER: PROPORTION OF ANIMALS REACHING TRACKING STATIONS}

Across the five treatments, the number of frog tracks recorded differed at all distances (Fig. 2), indicating an effect of cover type on the willingness of frogs to enter a given treatment (e.g. ANOVA for 10-m track model predictions; $F_{4,59}=2.73, P=0.03$ ). The proportion of tracks was consistently highest in the cornfield and the moderate-cover lawn, while the hayfield was the least permeable (ANOVA for 30-m model predictions; $F_{4,49}=$ $2.25, \mathrm{P}=0.07$; Fig. 2). The clear-cut and open lawn results were consistently similar and intermediate (observed proportions and model predictions; Fig. 2, Appendix S1). Using the proportion of animals reaching $30 \mathrm{~m}$ to infer movement success, the cornfield was 5.3 and 8.4 times more permeable than the open lawn and hayfield, respectively, while the moderate-cover lawn was 5.9 times more permeable than the hayfield.

\section{WILLINGNESS TO ENTER: PROPORTION OF RECAPTURES}

We released 561 frogs and recaptured $349(62.2 \%)$ across treatments and runways. Recapture rates ranged from $37.7 \%$ (hayfield) to $80.7 \%$ (cornfield), with intermediate rates in the clear-cut (49.5\%), moderate-cover lawn (69.6\%) and open lawn (73.2\%).

Classified by distance $(0,10,20$, and $30-35 \mathrm{~m})$, the percentage of captures varied by treatment $\left(\mathrm{X}^{2}{ }_{12}=92.6, \mathrm{P}\right.$ $<0.001$ ), indicating an effect of cover type on the willingness of frogs to enter. The majority of recaptures occurred at $0 \mathrm{~m}$ in the cornfield (68\%), lawns (open and moderate-cover; $64 \%$ and $51 \%$, respectively) and clear-cut (47\%), indicating a propensity for individuals to return to the forest (Fig. 3 ). The hayfield results

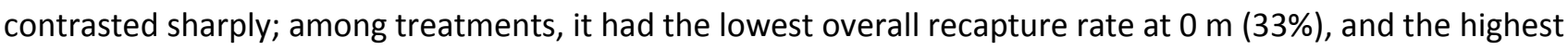


rate for all other distances (Table 1). Thus, frogs in the hay-field were significantly less likely to move towards the edge $(0 \mathrm{~m})$ compared with the cornfield $(P<0.001)$ and open lawn $(P<0.001)$. Furthermore, once in the hayfield, a significantly greater percentage $(29 \%)$ travelled the entire runway $(35 \mathrm{~m})$ compared with the cornfield ( $P=0.002 ; \mathrm{Fig} .3)$. The percentage of frogs travelling the entire runway was also high in the moderate-cover lawn (24\%), yet recapture rates were relatively low at $35 \mathrm{~m}$ in the cornfield $(7 \%)$ and open lawn (10\%, Fig. 3; Table 1), where ground vegetation structure was simple, but canopy was largely absent.

The distribution of recaptures at intermediate stations (10 and $20 \mathrm{~m}$ ) is noteworthy because they indicate animals changing directionality after entering a treatment (Fig. 3). Higher percentages of individuals were recaptured at $10 \mathrm{~m}$ in the hayfield (67\%) and lawn (open $42 \%$; moderate-cover $36 \%$ ) than in the clear-cut $(6 \%)$ and cornfield (24\%, Table 1$)$. At $20 \mathrm{~m}$, the hayfield maintained the highest capture rate $(33 \%)$, and the most exposed cover types (open lawn, cornfield) had the lowest recaptures ( $8 \%$ and $11 \%$, respectively).

\section{VELOCITY: MOVEMENT RATES AND TIMING OF MOVEMENTS}

Across all treatments, we obtained movement rates for 294 individuals recaptured past $10 \mathrm{~m}$ (which collectively traversed $4740 \mathrm{~m}$ during the 27 -day experiment). Average movement rates ranged between 8.9 and $55.6 \mathrm{~m}$ day -1 (Fig. 4 ) and differed significantly by cover type (ANOVA; F4,5 = 199.5, P < 0.001). We observed highest motility in the open and moderate-cover lawn treatments (55.6 and $54.1 \mathrm{~m} \mathrm{day}^{-1}$, respectively), and lower rates in the clear-cut $\left(30.4 \mathrm{~m} \mathrm{day}^{-1}\right)$, cornfield $\left(26.7 \mathrm{~m} \mathrm{day}^{-1}\right)$ and hayfield $(8.9 \mathrm{~m}$ day $^{-1}$; Fig. 4). There was a strong negative relationship between the observed proportion of juveniles entering a treatment and the movement rate within that treatment (Fig. 4; $=0.44 ; r=-0.66$; d.f. $=4 ; \mathrm{R} 2 \mathrm{P}<$ 0.01). For example, the hayfield represented the least permeable treatment according to velocity $(8.9 \mathrm{~m}$ $\mathrm{day}^{-1}$ ); yet, we observed the highest proportion of released frogs enter this cover type ( 0.68 out of total released; Fig. 4). Most movements occurred within the first 3 days post-release, but within this period, we found differences in the timing of movements by treatment (Fig. 5a-c). Individuals in the cornfield, clear-cut and moderate-cover lawn made the earliest (and longest) forays into runways, while the hayfield and open lawn were permeated slowly (only $5.3 \%$ reaching $20 \mathrm{~m}$ in the hayfield by day 3; Fig. 5a-c). Across all treatments (and on average), 7.5\% reached $30 \mathrm{~m}$. Juveniles moved quickly once a direction was selected, with the exception of the hayfield (Fig. 5c). The majority of recaptures occurred within the first 3 days post-release (91\%) with only 33 animals spending > 3 days in runways (12: hayfield; 10: cornfield; 6: moderate-cover lawn; 4: open lawn; 1: clear-cut).

\section{MICROCLIMATE AND MICROHABITAT FEATURES}

We observed moderate differences in microclimate between treatments (Table 2). Compared with the mature forest stands studied by Popescu and Hunter (2011), our ground-level maximum daily temperatures were, on average, $10.2-12.6^{\circ} \mathrm{C}$ higher (2008-09, Table 2). The highest ground temperature was $42.3^{\circ} \mathrm{C}$, recorded in the cornfield (13:00 h, 9 July 2010). The clear-cut, hayfield and moderate-cover lawn treatments were the driest (\% relative humidity; Table 2 ). All treatments had $0 \%$ tree cover, except the moderate-cover lawn (45-85\% canopy). In clear-cuts, the herbaceous stratum had the greatest coverage $(55.0 \%)$ and shrub cover was $11 \%$. In the cornfield, the average inter-row distance was $1.1 \mathrm{~m}$; average crop height grew from 1.6 to $2.8 \mathrm{~m}$ (16-29 July 2010). The hay-field had a tall, dense sward of grasses and legumes, with average stem height of $0.87 \mathrm{~m}$ (negligible differences between sampling dates) and density of 3280 stems $\mathrm{m}-2$. The lawns had high stem densities (10 760 in moderate-cover; 12880 in open lawn) but were much shorter: the open lawn grass grew from 10.7_to $17.4 \mathrm{~cm}$ between 16 and 29 July 2010, while the moderate-cover lawn was lower ( 8.6 and $11.4 \mathrm{~cm}$ on 16 and 22 July 2010 , respectively). 
In contrast to the traditional habitat-matrix paradigm, in which 'habitat' is classified as hospitable and 'matrix' as uniformly hostile (Hudgens et al. 2012), it is now recognized that species may perceive landscapes in complex ways, for example, using resources from different land-cover types during dispersal. We tested the movements of juvenile L. sylvaticus in open-cover habitat types to evaluate how vegetation type affects permeability during dispersal, a critical stage for population connectivity. Few empirical studies have measured the effects of open cover on amphibian ranging, and most of these have compared the permeability of forest to one type (e.g. old fields: Rothermel \& Semlitsch 2002; grasslands: Rittenhouse \& Semlitsch 2006; clear-cuts: Popescu \& Hunter 2011). In agroecosystems, crop-specific dispersal was compared for Ambystoma tigrinum (Cosentino, Schooley \& Phillips 2011) and Rana temporaria (Vos et al. 2007). This study is among the first to measure relative permeabilities across a broad spectrum of land-uses that generate open cover, with our index (Appendix S2) suggesting that permeability was lowest in row crops, increased in hayfields, clear-cuts and open lawns and was highest in moderate-cover lawn. This pattern indicates that these are differential ecological filters to movements, and thus, it is overly simplistic to assume dispersal success is singularly low across all open-cover types.

\section{HABITAT STRUCTURE AND LOCOMOTION}

Our results suggest that the hayfield and clear-cut may constitute physical filters to movement (i.e. locomotion constrained by dense ground vegetation), while the openness of the lawn and cornfield may have allowed faster movement. Although we predicted that open treatments would afford increased velocities for juvenile frogs, we did not anticipate the observed negative relationship between movement rate and an individual's willingness to enter a given treatment (Fig. 4). Taken together, this suggests that simplified vegetation structure represented low impedance for locomotion, but that other factors (such as perceived predation or desiccation risk) may also shape entry decisions at the forest edge. In not one case did we observe a juvenile reach the 35-m mark during a single-night foray in the hayfield or clear-cut. Moreover, velocities in the hayfield suggest that individuals may persist in this cover type up to 3 days, post-release; this is a prolonged residency that we predicted for dense vegetation, although this result was rarely observed in other treatments (Fig. 5c). Conversely, frogs in the cornfield and lawn exhibited more movement, evidenced by (1) higher overall recapture rates at 30-35 m, a result that was not predicted (Table 1); (2) greater number of single-night forays to the end of runways (Fig. 5a, Table 1); and (3) greater average velocity (Figs 4 and 5). Previous studies have demonstrated that locomotor performances of amphibians depend on the nature of the surface component crossed (e.g. Eycott et al. 2012).

\section{POTENTIAL INFLUENCE OF MICROCLIMATE ON PERMEABILITY}

Microclimate conditions play a role in the spatial ecology of amphibians (Rittenhouse et al. 2008), but our results suggest limited links between temperature, humidity and the physiology of frog performance. Our observed high temperatures and dry microclimates in the clear-cut (Table 2) are consistent with low observed and predicted permeability in that treatment (Appendix S1; Table 1). However, another low-permeability cover type, open lawn, had the highest relative humidity values and temperatures similar to other treatments, an unexpected result. Overall, most of our observed differences in microclimate were modest (Table 2), perhaps due to the relatively cool, moist climate of Maine, or perhaps due to the scale of our measurements (three per runway, one each for ground, air and refugia). This contrasts with a number of studies, suggesting that microclimate is a primary influence driving amphibian movements (e.g. Rittenhouse et al. 2008). 


\section{DIRECT MORTALITY IN OPEN-CANOPY MATRIX HABITATS}

Both microclimate and predation risk may influence the frequency and causation of direct mortality for post-metamorphic frogs, and these factors shaped our predictions for juvenile movements. For example, we expected open-canopy cover to have high risks of desiccation mortality if individuals could not find cool, damp refuge during afternoons; anecdotally, we observed six deaths by desiccation in open lawn and 11 in cornfield. In open lawn, our most open treatment, this issue was avoided, at least by some frogs, which were released in the evening and captured at $35 \mathrm{~m}$ the following morning. As predicted, this never occurred in our least permeable and coolest treatment (hayfield: Table 2). We speculate that hayfield frogs could not travel through $35 \mathrm{~m}$ of thick vegetation in one night, but that this treatment offered diurnal refugia for short-term persistence (Figs 4 and 5c). Predation is also likely to be higher in open cover than in forests (Barbasch \& Benard 2011). We did not measure predator abundance, but anecdotally, we detected numerous Thamnophis sirtalis (garter snakes) in the hayfield, clear-cut and cornfield sites, and we observed diurnal and nocturnal raptors (e.g. Strix varia, Buteo jamiacensis) near our agricultural treatments. If predation risk influences dispersal success, the occurrence of $T$. sirtalis in the clear-cut and hayfield would align with their low permeability (Figs 1 and 4).

\section{SINGLE FACTORS DO NOT EXPLAIN JUVENILE MOVEMENTS}

We predicted that animals will respond to the interactive effects of vegetative cover, microclimate, presence of predators and other factors such as landscape configuration during dispersal; thus, we would be unlikely to explain juvenile movements based on single factors. For example, the hayfield and open lawn represented the strongest filters to movement (Fig. 2), yet these treatments had the greatest difference in relative humidity (58.83\% and $75.30 \%$, respectively) and understorey vegetation, and the second greatest difference in maximum daily ground temperatures $\left(29.7^{\circ}\right.$ and $39.2^{\circ}$ ) between cover types (Table 2 ). Thus, there may be a conflicting role of the hayfield as a filter and conduit to dispersal, since it may afford more cover, but at the cost of (1) increased desiccation risk (low humidity, due to increased water-use efficiency of hay-crop species) and (2) greater impediments to locomotion (Fig. 4). We posit that frogs were responding to an interplay of ecological pressures that reach beyond the factors discussed above to include density-dependent effects (Patrick et al. 2008), food availability, agrochemical or pollutants, floral composition or range of perception (Vos et al. 2007).

\section{THE EVACUATION HYPOTHESIS AND FATE OF NONDETECTED JUVENILES}

Our data suggest that individuals may enter open cover during ranging, assess habitat quality and subsequently change their decision. This is consistent with the 'evacuation hypothesis' following clear-cutting (Semlitsch et al. 2008), as well as our prediction that a greater proportion of animals would return to the forest edge when released in our most open treatments (lawns, cornfields; Fig. 3).

However, relatively high recapture rates at $35 \mathrm{~m}$ in the hayfield (29\%), moderate-cover lawn (24\%) and clear-cut (20\%) also suggest that individuals can travel an entire runway, once they made the decision to travel past 10 and $20 \mathrm{~m}$. Furthermore, some of the longest single-distance movements (i.e. $35 \mathrm{~m}$ per night) occurred during dry ambient conditions. This indicates that juveniles may depart and move quickly through open treatments, once a direction is selected, corroborating results in clear-cuts (Table 1: Popescu \& Hunter 2011). Lower recapture and track rates in the hayfield and clear-cut indicated that they probably served as sources of refuge or mortality, a result that aligns with predictions (Table 1, Fig. 2). In our experiment, we cannot distinguish the fate of missing frogs with respect to mortality, trespass and settling in the runway or assess realized connectivity (i.e. survival to reproduction). 


\section{FUTURE STUDIES AND MANAGEMENT IMPLICATIONS}

To fully understand dispersal in heterogeneous, complex landscapes, we need long-term studies of individual ranging behaviour in different cover types, both those typically deemed suitable habitat, as well as those that might facilitate dispersal, but not be used during other life stages. Our study only provides a one-season window into the processes driving movements in human-altered landscapes. Our runway 'self-tracking' design provides a minimally invasive way to record fine-scale ranging behaviour, but a more complete understanding of the effects of open cover on dispersal requires long-term monitoring of individual fitness and behaviour using direct tracking, although this remains a challenge for small-bodied organisms. We also need to assess how land management practices such as crop-rotation, thinning, harvest, mowing, pesticide application or frequency of human disturbance or entry can be best designed (and situated within larger landscapes and across time) to facilitate dispersal. Disturbance intervals range from weeks in lawns to decades in clear-cuts, and some disturbances happen during dispersal periods and some only in other seasons.

We have demonstrated that open-canopy cover types may differ as ecological filters to juvenile movements, and these distinctions may inform land-use planning; for example, how the composition and configuration of these cover types should be integrated with forest distribution to reduce the 'effective' isolation of (and not just Euclidean distance between) preferred habitats. These distinctions are also important because many landscape population dynamics analyses use expert-based permeability values that are a one-size-fits-all measure for open cover (Hudgens et al. 2012). Our study provides a repeatable assessment of permeability at the scale of individual cover types and a quantitative permeability index, which can be used to parameterize models for amphibians, although we urge caution in the widespread application of this numeric index to other study species or regions (see Appendix S2). Future research could use our understanding of the mechanistic aspects of permeability to explore movement through assemblages of different cover types ('landscape heterogeneity' scale), once technological capacity permits direct tracking of individuals over long distances. Thus, we also need field-based, direct measures of the mechanisms that influence ranging behaviour and dispersal success in heterogeneous settings, in order to predict and effectively maintain functional connectivity in fragmented landscapes.

\section{Acknowledgements}

This work was supported by the National Science Foundation under Grants 0239915 and EPS-0904155 (to the Maine EPSCoR Sustainability Solutions Initiative), the Maine Association of Wetland Scientists, and the Maine Agricultural and Forest Experiment Station (MAFES). We thank Joseph Cannon, Jake Dyer and Brad Libby for support with site selection; Viorel Popescu, Jonathan Grant, Scott Helmke, Dawn Morgan, Scott Parkhill and Sabrina Vivian for field assistance; Viorel Popescu for statistical advice; and Joseph Zydlewski, Aram Calhoun, Robert Seymour and David Hiebeler and two anonymous reviewers for critiques on prior versions of the manuscript. This is MAFES paper 3361. 
References

Barbasch, T. \& Benard, M.F. (2011) Past and present risk: exposure to predator chemical cues before and after metamorphosis influences juvenile wood frog behavior. Ethology, 117, 367-373.

Beelisle, M. (2005) Measuring landscape connectivity: the challenge of behavioral landscape ecology. Ecology, 86, 1988-1995.

Berven, K.A. \& Grudzien, T.A. (1990) Dispersal in the wood frog (Rana sylvatica): implications for genetic population structure. Evolution, 44, 2047-2056.

Bowler, D.E. \& Benton, T.G. (2005) Causes and consequences of animal dispersal strategies: relating individual behaviour to spatial dynamics. Biological Reviews, 80, 205-225.

Burgess, S.C., Treml, E.A. \& Marshall, D.J. (2012) How do dispersal costs and habitat selection influence realized population connectivity? Ecology, 96, 1378-1387.

Clobert, J., LeGallliard, J., Cote, J., Meylan, S. \& Massot, M. (2009) Informed dispersal, heterogeneity in animal dispersal syndromes and the dynamics of spatially structured populations. Ecology Letters, 12,197-209.

Cosentino, B.J., Schooley, R.L. \& Phillips, C.A. (2011) Connectivity of agroecosystems: dispersal costs can vary among crops. Landscape Ecology, 26, 371-379.

Desrochers, R.E., Kerr, J.T. \& Currie, D.J. (2011) How, and how much, natural cover loss increases species richness? Global Ecology and Biogeography, 20, 857-867.

Dingle, H. (1996) Migration: The Biology of Life on the Move, 1st edn.

Oxford University Press, New York. Dingle, H. \& Drake, V.A. (2007) What is migration? BioScience, 57, 113-121. Eycott, A.E., Stewart, G.B., Buyyng-Ali, L.M., Bowler, D.E., Watts, K. \&

Pullin, A.S. (2012) A meta-analysis on the impact of different matrix structures on species movement rates. Landscape Ecology, 27, 1263-1278.

Fox, J. \& Weisberg, S. (2011) An R Companion to Applied Regression, 2nd edn. Sage, Blackwood Oaks, California. http://CRAN.R-project.org/ package=car.

Gosner, K.L. (1960) A simplified key for staging anuran embryos and larvae with notes on identification. Herpetologica, 16, 183-190.

Hothorn, T., Hornik, K., van de Wiel, M.A. \& Zeileis, A. (2008) Implementing a class of permutation tests: the coin package. Journal of Statistical Software, 28,1-23.

Hudgens, B.R., Morris, W.F., Haddad, N.M., Fields, W.R., Wilson, J.W., Kuefler, D. \& Jobe, T. (2012) How complex do models need to be to predict dispersal of threatened species through matrix habitats? Ecological Applications, 22, 1701-1710.

Janin, A., Leena, J.-P., Deblois, S. \& Joly, P. (2012) Use of stress-hormone levels and habitat selection to assess functional connectivity of a landscape for an amphibian. Conservation Biology, 26, 923-931.

Kuefler, D., Hudgens, B., Haddad, N.M., Morris, W.F. \& Thurgate, N. (2010) The conflicting role of matrix habitats as conduits and barriers for dispersal. Ecology, 91, 944-950.

deMaynadier, P.G. \& Hunter, M.L. Jr (1998) Effects of silvicultural edges on the distribution and abundance of amphibians in Maine. Conservation Biology, 12, 340-352.

Patrick, D.A., Harper, E.B., Hunter, M.L. Jr \& Calhoun, A.J.K. (2008) Terrestrial habitat selection and strong density-dependent mortality in recently metamorphosed amphibians. Ecology, 89, 2563-2574.

Popescu, V.D. \& Hunter, M.L. Jr (2011) Clearcutting affects habitat connectivity for a forest amphibian by decreasing permeability to juvenile movements. Ecological Applications, 21, 1283-1295.

Revilla, E., Wiegand, T., Palomares, F., Ferreras, P. \& Delibes, M. (2004) Effects of matrix heterogeneity on animal dispersal: from individual behavior to metapopulation-level parameters. The American Naturalist, 164, E130-E153. 
Rittenhouse, T.A.G. \& Semlitsch, R.D. (2006) Grasslands as movement barriers for a forest-associated salamander: migration behavior of adult and juvenile salamanders at a distinct habitat edge. Biological Conservation, 131,14-22.

Rittenhouse, T.A.G., Harper, E.B., Rehard, L.R. \& Semlitsch, R.D. (2008) The role of microhabitats in the dessication and survival of anurans in recently harvested oak-hickory forest. Copeia, 4, 807-814.

Rothermel, B.B. \& Semlitsch, R.D. (2002) An experimental investigation of landscape resistance of forest versus old-field habitats to emigrating juvenile amphibians. Conservation Biology, 16, 1324-1332.

Semlitsch, R.D. \& Bodie, J.R. (2003) Biological criteria for buffer zones around wetlands and riparian habitats for amphibians and reptiles. Conservation Biology, 17, 1219-1220.

Semlitsch, R.D., Connor, C.A., Hocking, D.J., Rittenhouse, T.A.G. \& Harper, E.B. (2008) Effects of timber harvesting on pond-breeding

amphibian persistence: testing the evacuation hypothesis. Ecological Applications, 18, 283-289. Van Buskirk, J. (2012) Permeability of the landscape matrix between amphibian breeding sites. Ecology and Evolution, 2, 3160-3167. Vos, C.C., Goedhart, P.W., Lammertsma, D.R. \& Spitzen-Van der Sluijs,

A.M. (2007) Matrix permeability of agricultural landscapes: an analysis of movements of the common frog (Rana temporaria). Herpetological Journal, 17, 174-182.

Zeller, K.A., McGarigal, K. \& Whiteley, A.R. (2012) Estimating landscape resistance to movement: a review. Landscape Ecology, 27, 777-797.

Supporting Information

Additional Supporting Information may be found in the online version of this article.

Appendix S1. Observed and predicted proportions of released juvenile Lithobates sylvaticus reaching 10-, 20-, and 30-m distances (from perpendicular interface with forest edge) in five open canopy cover treatments in 2010.

Appendix S2. Quantitative index of the permeability of our five open-canopy vegetation types to juvenile movements of Lithobates sylvaticus during the post-metamorphic period in 2010, with mature forest as a control (permeability $=1.0$ ). 
Figure 1
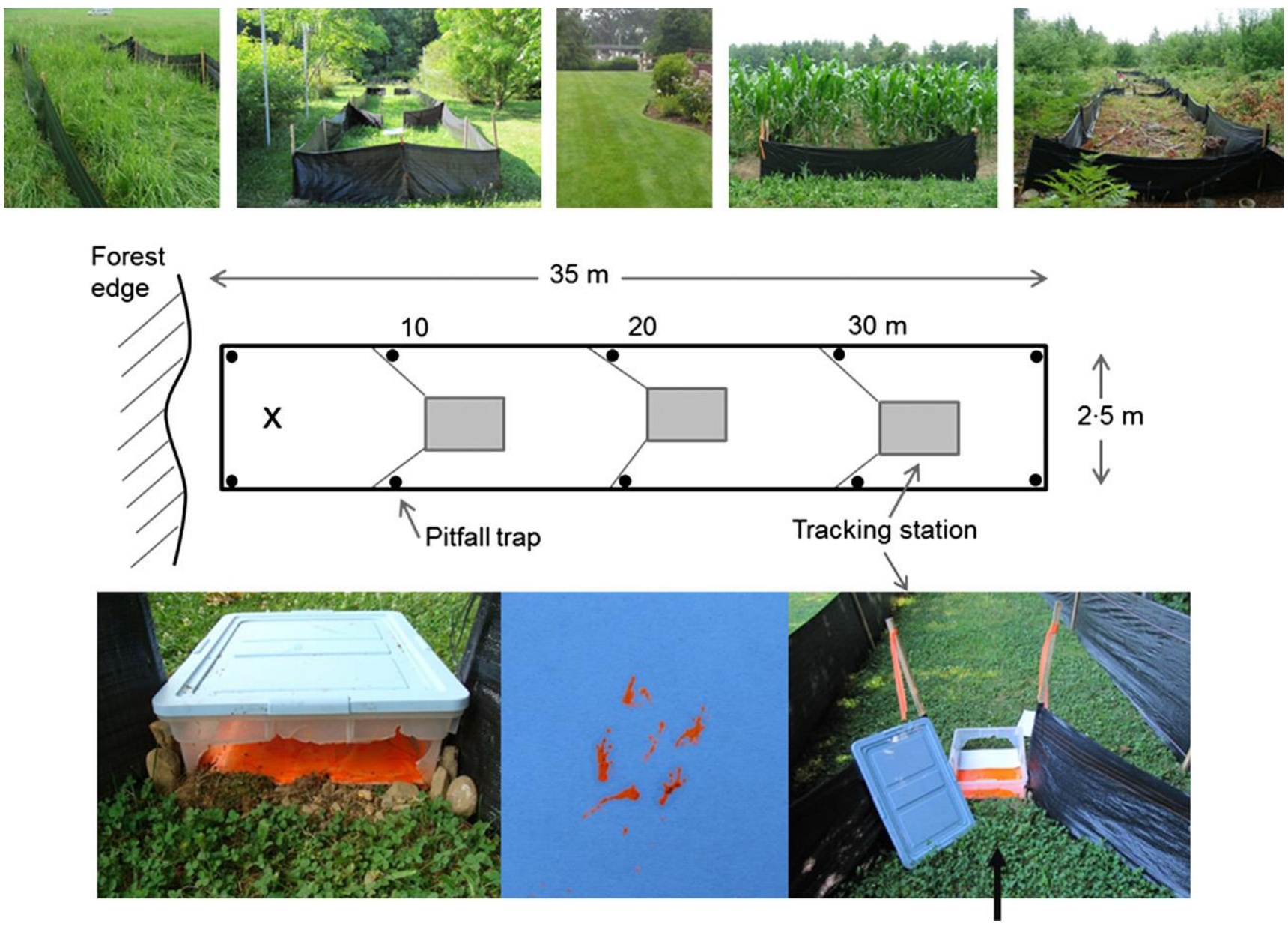

Figure 1 Experimental design for evaluating the permeability of five open-canopy cover types to juvenile wood frogs Lithobates sylvaticus during post-metamorphic dispersal. The top panel depicts the five treatments tested: (a) hayfield, (b) lawn (45-85\% cover), (c) lawn (0\% cover), (d) row crop (feed corn) and (d) forest clearcut. The middle panel illustrates tracking station design; $\mathrm{x}$ indicates initial release (drawing not to scale; adapted from Popescu \& Hunter 2011). The bottom panel depicts fluorescent powder tracks; the arrow denotes runway directionality. 
Figure 2

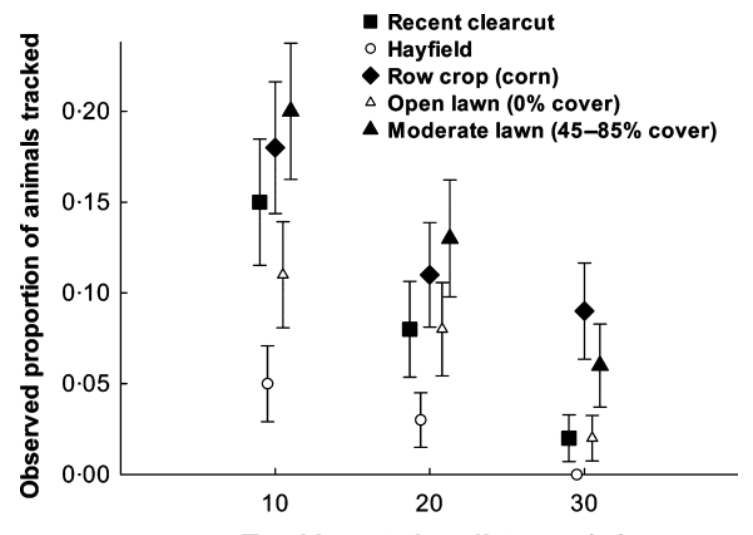

Tracking station distance $(\mathbf{m})$

Figure 2 Observed proportions of juvenile L. sylvaticus reaching:

(a) 10-m, (b) 20-m and (c) 30-m tracking stations in five open-cover types (mean $\pm \mathrm{SE}$ ). Values on $\mathrm{y}$-axis are observed proportions of released individuals moving through stations averaged across runways and batches (mean $\pm 1 \mathrm{SE}$ ). 
Figure 3

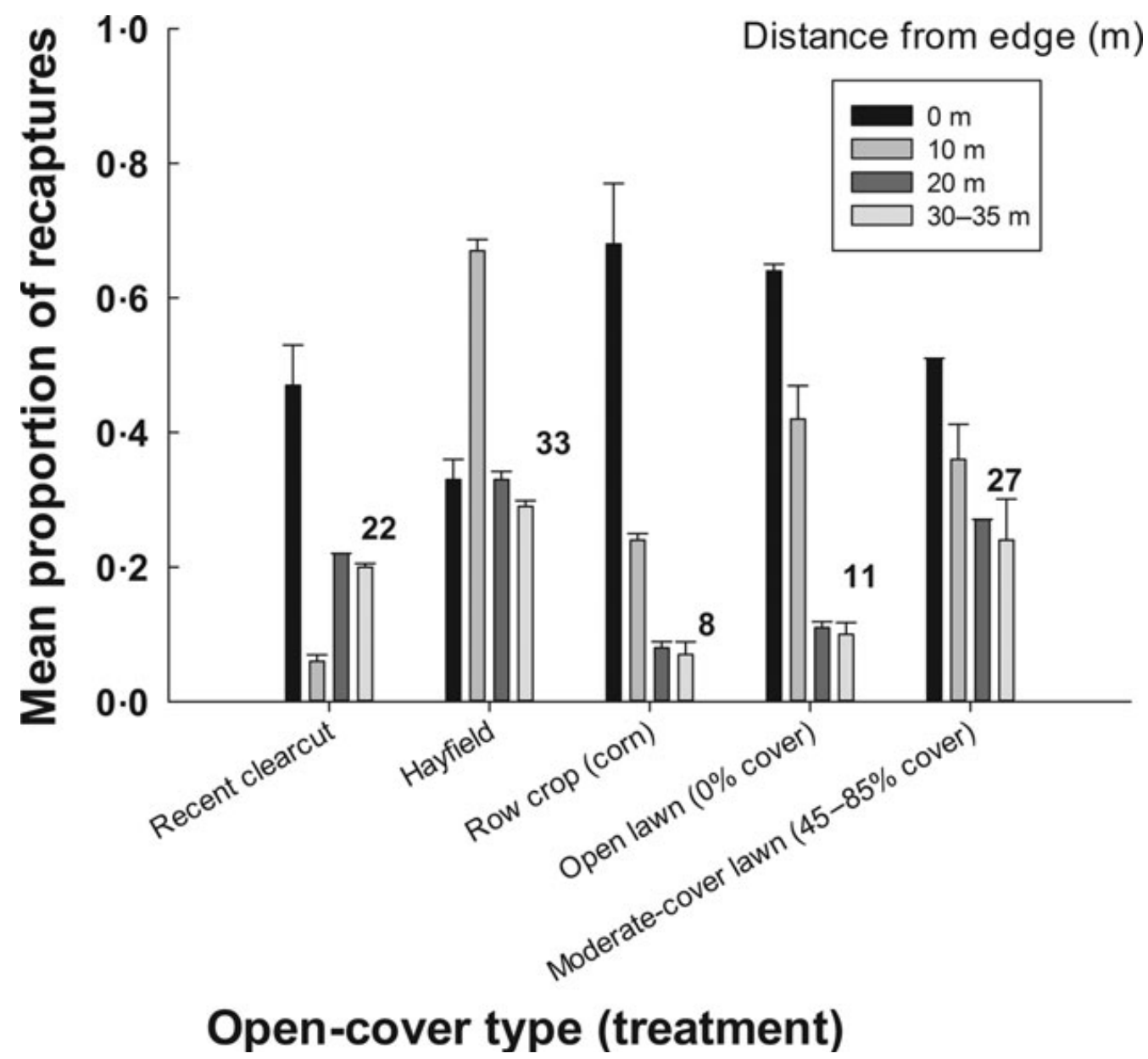

Figure 3 Proportion of juvenile L. sylvaticus reversing movement direction in runways, categorized by five treatments and four distances. Values on the y-axis are observed proportions of released animals that were recaptured in pitfall traps (mean $\pm 1 \mathrm{SE}$, across runways and batches) at four distances $(0,10,20,30-35 \mathrm{~m})$. Recaptures at $0 \mathrm{~m}$ indicate low matrix permeability (high resistance), at $35 \mathrm{~m}$ indicate high permeability (low resistance) and at intermediate stations denote a change in direction (forest edge). Percentage values indicate the proportion of individuals reaching $35 \mathrm{~m}$ of total released for each treatment $(\mathrm{n}=109-114)$. 
Table 1 Percentage (\%) of juvenile wood frogs Lithobates sylvaticus recaptured in experimental runways, categorized by five open-canopy cover types (treatments) in 2010, and two reference treatments (forest clear-cut and mature forest) in 2008-09

Individuals recaptured $(\%)$, by tracking distance $(\mathrm{m})$

\begin{tabular}{|c|c|c|c|c|c|}
\hline $\begin{array}{l}\text { Open-canopy cover } \\
\text { type (treatment) }\end{array}$ & No. juveniles released & $0 \mathrm{~m}$ & $10 \mathrm{~m}$ & $20 \mathrm{~m}$ & $\begin{array}{l}30 \text { and } 35 \mathrm{~m}(2010) \\
40 \text { and } 50 \mathrm{~m}(2008-09)\end{array}$ \\
\hline 2010 recapture & $349(561)$ & & & & \\
\hline Forest clear-cut* & 109 & $47^{\mathrm{A}}$ & 6 & 22 & 20 \\
\hline Hayfield & 114 & $33^{\mathrm{B}}$ & 67 & 33 & $29^{\mathrm{A}}$ \\
\hline Row crop (feed corn) & 114 & $68^{\mathrm{AB}}$ & 24 & 8 & $7^{\mathrm{AB}}$ \\
\hline Lawn $(0 \%$ cover $)$ & 112 & $64^{\mathrm{B}}$ & 42 & 11 & $10^{\mathrm{A}}$ \\
\hline Lawn $(\sim 45-85 \%$ cover $)$ & 112 & $51^{\mathrm{B}}$ & 36 & 27 & $24^{\mathrm{B}}$ \\
\hline \multicolumn{6}{|l|}{2009 recapture } \\
\hline Forest clear-cut* & 118 & 48 & 24 & 5 & 7 \\
\hline Mature forest & 117 & 18 & 11 & 0 & 31 \\
\hline \multicolumn{6}{|l|}{2008 recapture } \\
\hline Forest clear-cut* & 112 & 30 & 23 & 13 & 11 \\
\hline Mature forest & 133 & 19 & 5 & 0 & 29 \\
\hline
\end{tabular}


Figure 4

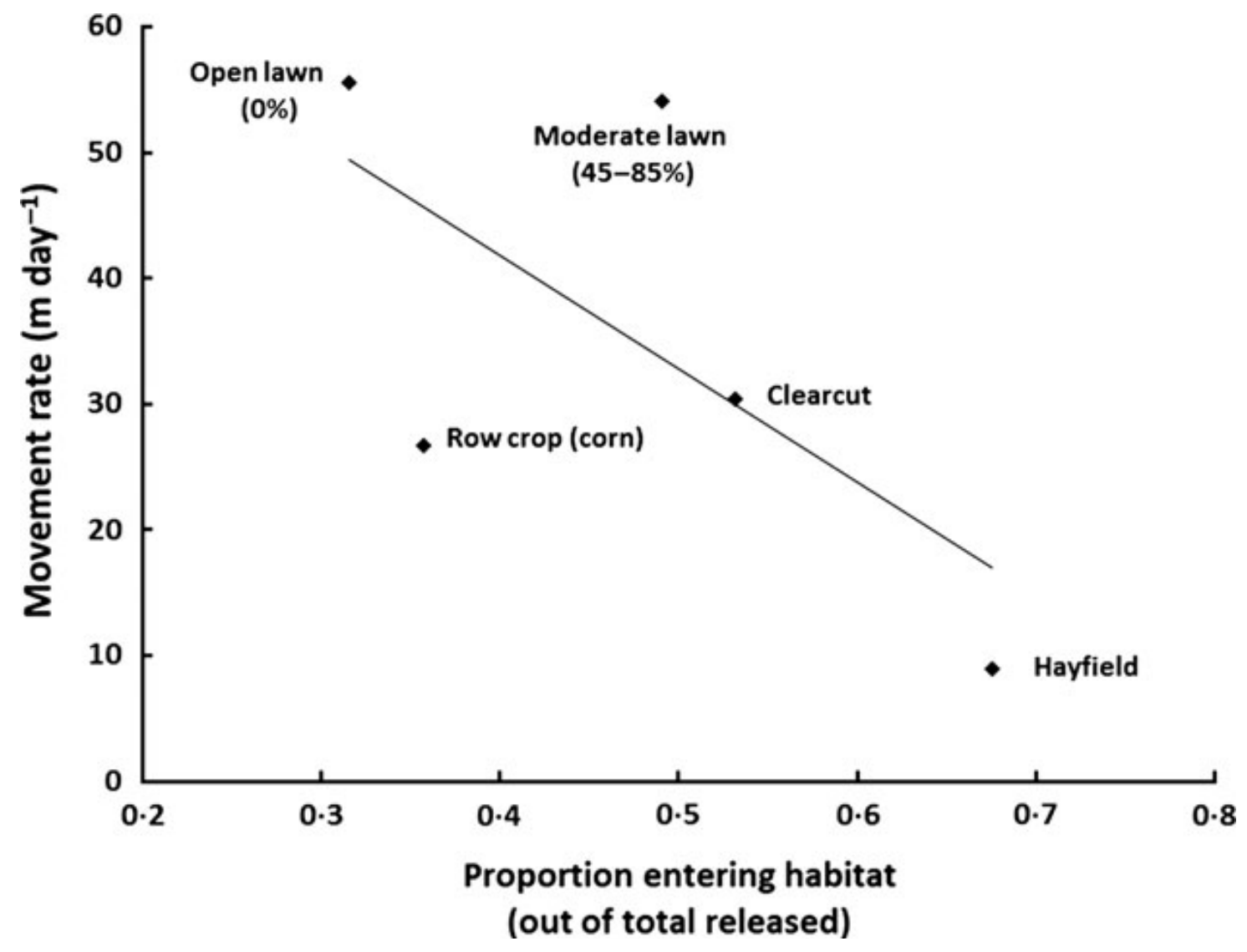

Figure 4 Relationship between the observed proportion of juvenile L. sylvaticus entering a treatment and movement rate within that treatment. The observed proportion entering a treatment is the proportion recaptured at 10, 20 or 30-35 m (but not $0 \mathrm{~m}$ ) of the total released (mean $\pm 1 \mathrm{SE}$ averaged across runways and batches). The movement rate $\left(\mathrm{m} \mathrm{day}^{-1}\right)$ is the average for 294 individuals tracked past $10 \mathrm{~m}$. 
Figure 5

(a) Day 1 post-release juvenile Lithobates sylvaticus
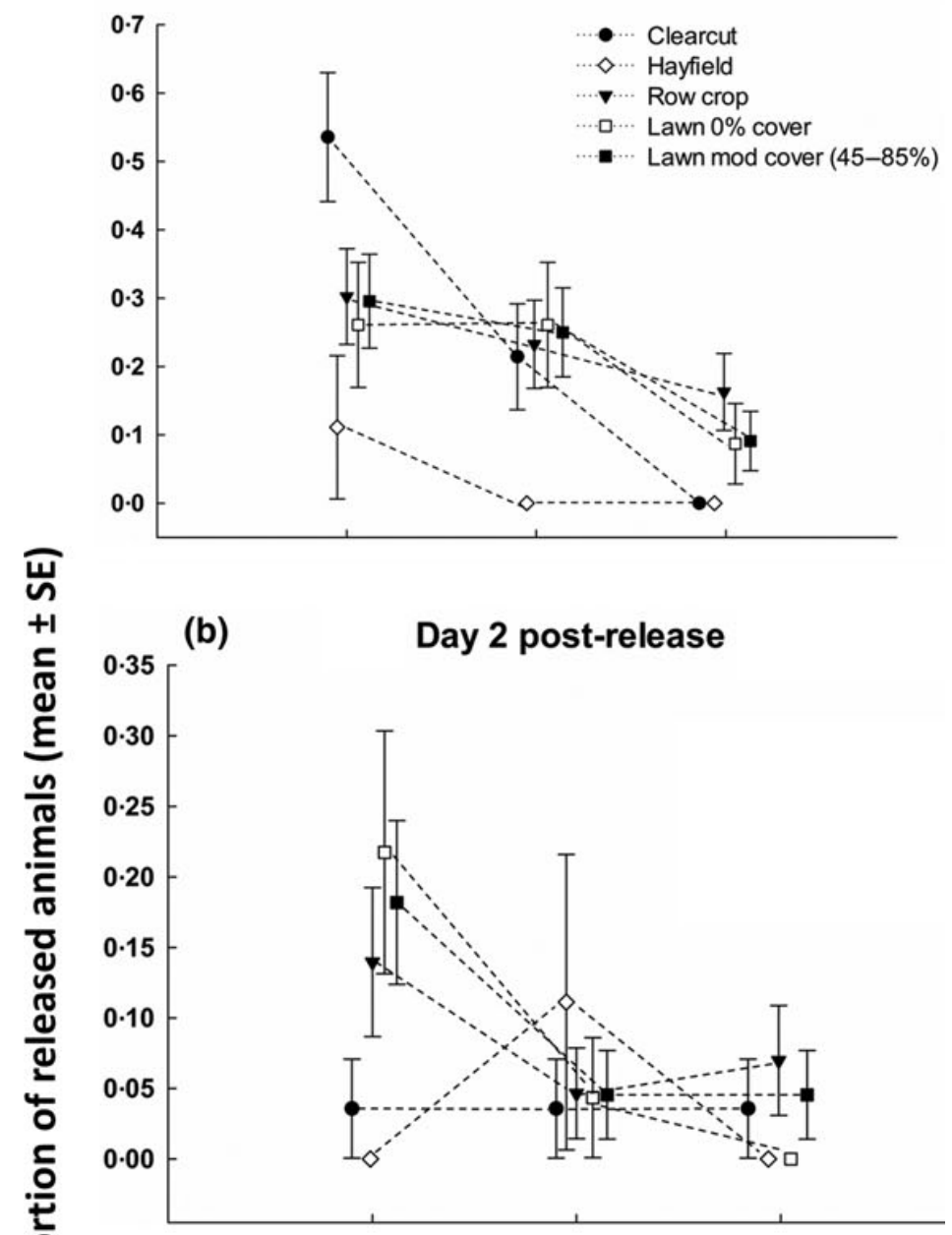

(c)

Day 3 post-release

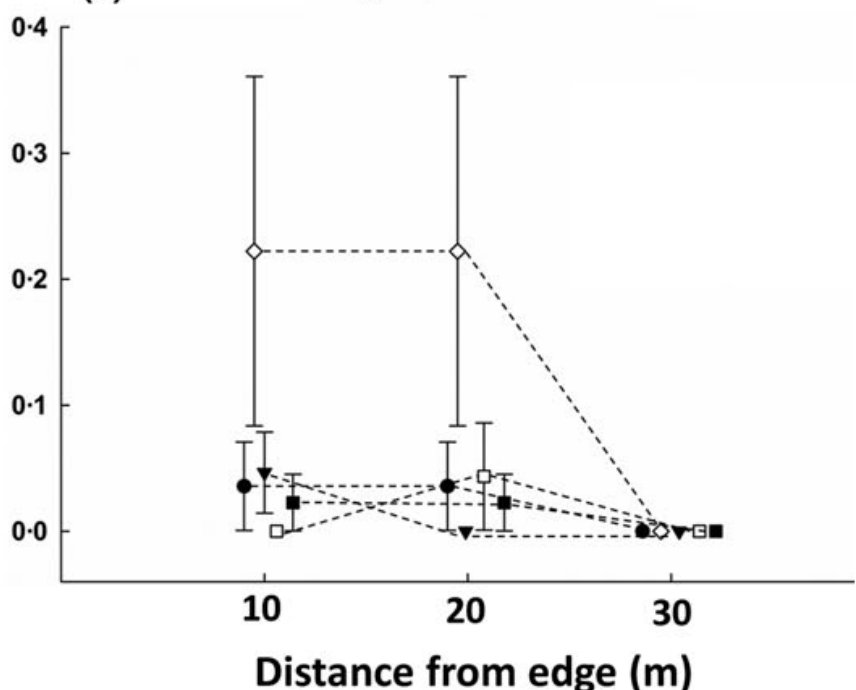

Figure 5 Timing of movements of juvenile L. sylvaticus experimentally released in five open-canopy treatments. The proportion of released individuals (y-axis) denotes the number moving through each station (averaged across runways and batches) relative to the total number of tracks recorded per runway (mean $\pm 1 \mathrm{SE}$ ). The first 3 days post-release accounted for the majority of movement, with the exception of hayfield (note scale-bar difference for days 1 vs. 2 and 3). Because some individuals remained in the runways from earlier releases, it is possible for the numbers at distant stations to exceed those at close stations (e.g. compare 10 and $20 \mathrm{~m}$ in open lawn in panel c). 
Table 2 Mean daily maximum temperature $\left({ }^{\circ} \mathrm{C}\right.$ ) and relative humidity (\%) of five open-canopy cover types (treatments) during experimental amphibian releases. Microclimate data are compiled for dates inclusive of frog movement through experimental runways (8 July7 August 2010) and were recorded at ground- and refugia-levels in each runway

\begin{tabular}{|c|c|c|c|c|}
\hline \multirow[b]{2}{*}{ Treatment } & \multicolumn{3}{|c|}{ Mean daily maximum temperature $\left({ }^{\circ} \mathrm{C}\right)$} & \multirow{2}{*}{$\begin{array}{l}\text { Relative humidity (\%) } \\
\text { Ground level }\end{array}$} \\
\hline & Ground level & Refugia & Air & \\
\hline \multicolumn{5}{|l|}{2010} \\
\hline Forest clear-cut & 33.5 & $27 \cdot 3$ & $34 \cdot 9$ & $60 \cdot 0 \pm 3 \cdot 2$ \\
\hline Hayfield & $29 \cdot 7$ & $25 \cdot 4$ & $32 \cdot 8$ & $58 \cdot 8 \pm 3 \cdot 3$ \\
\hline Row crop (feed corn) & $31 \cdot 6$ & $26 \cdot 3$ & 31.9 & $69 \cdot 6 \pm 3 \cdot 5$ \\
\hline Lawn $(0 \%$ cover $)$ & $33 \cdot 2$ & - & $32 \cdot 8$ & $75 \cdot 3 \pm 3 \cdot 6$ \\
\hline Lawn (moderate, $\sim 45-85 \%$ cover) & $31 \cdot 1$ & - & $32 \cdot 5$ & $60 \cdot 2 \pm 3 \cdot 6$ \\
\hline \multicolumn{5}{|l|}{2008 reference } \\
\hline Forest clear-cut & $31 \cdot 6$ & $23 \cdot 4$ & - & $62 \cdot 9 \pm 6 \cdot 3$ \\
\hline Mature forest & $23 \cdot 0$ & $18 \cdot 7$ & - & $78 \cdot 7 \pm 4 \cdot 5$ \\
\hline \multicolumn{5}{|l|}{2009 reference } \\
\hline Forest clear-cut & $26 \cdot 3$ & $22 \cdot 1$ & _- & $86 \cdot 3 \pm 1.9$ \\
\hline Mature forest & $20 \cdot 9$ & $17 \cdot 0$ & - & $96 \cdot 8 \pm 1 \cdot 0$ \\
\hline
\end{tabular}

